\title{
Overview of mine scheduling for Oyu Tolgoi Underground Project
}

\author{
S Fowke Rio Tinto, Australia \\ B Groeneveld Rio Tinto, Australia
}

\begin{abstract}
Mine scheduling at Oyu Tolgoi (OT) Underground Project is centred on executing the perfect shift. This paper will outline the best practice mine scheduling process used at OT with an overview of the structure and mechanics. Scheduling commences by the Mine Planning and Technical team offsite with plans transitioned to site for detailing in the three-month execution space. Mine development scheduling involves developing a build-up of activities that represent the latest mine design. The development tasks cover a range of ground support profiles based on life-of-mine requirements for the excavations and ground conditions, with task rates developed from first principles.

Simulation is used to validate and test these rates in the schedule. The schedule is resource levelled, taking into account mine priorities, a calendar of working hours and system constraints. The schedule is integrated with construction planning through a number of defined interface points. Following this, plans are submitted to the Integrated Planning Process (IPP) where additional conflicts are identified and resolved. This paper will demonstrate how at $O T$, the mine planning process is structured and integrated with the whole project to ensure competing priorities are evaluated equally across the project.
\end{abstract}

Keywords: mine scheduling, resource levelling, management operating system, mine development

\section{Introduction}

The Oyu Tolgoi (OT) copper and gold project is located in the Omnigovi province of Mongolia, situated approximately $500 \mathrm{~km}$ south of the capital, Ulaanbaatar, and $80 \mathrm{~km}$ north of the border with China, in the Southern Gobi region of Mongolia (Figure 1). OT consists of a series of deposits containing copper, gold, silver, and molybdenum. The deposits lie in a structural corridor where mineralisation has been discovered over a $26 \mathrm{~km}$ strike length from Ulaan Khud in the north and Javkhlant in the south.

Sinking of Shaft 1 for the underground project commenced in 2005 with completion in 2008. Sinking of Shaft 2 and Shaft 5 was commenced in July 2006 and April 2013, respectively. Off-shaft lateral development was commenced in March 2008. A total of $16 \mathrm{~km}$ of lateral development was undertaken from Shaft 1 . Shaft 2 and Shaft 5 had reached a depth of 1,167 m and $208 \mathrm{~m}$, respectively, before the underground project was placed into care and maintenance in August 2013. An open pit and concentrator has been in commercial production since September 2013. In July 2016, the Hugo North Lift 1 underground project was formally re-commenced.

Panel caving was selected for OT due to the large orebody and good ground conditions for caving. The Hugo North orebody is approximately $225 \mathrm{~m}$ wide, 2,000 m long, and 1,000 $\mathrm{m}$ high. The underground project currently underway is the planned first lift of the orebody, with a lift height of $+500 \mathrm{~m}$ and an average column height of $350 \mathrm{~m}$. Based on current data, the critical hydraulic radius (HR) to initiate and sustain caving of the rock mass is approximately 20-23 m. The Mining Rock Mass Rating (MRMR) of 40-45 is highly caveable at a critical HR $>20-23 \mathrm{~m}$, for the median values for porphyritic quartz monzodiorite (QMD), porphyritic augite basalt (VA), and dacitic tuff (IGN). Values for the QMD and VA represent most of the orebody. The Hugo North orebody is highly faulted throughout, and fault-bound on the east and west by sub-vertical faults. 
While the overall rock mass strength is fair, the highly fractured nature of the orebody, in addition to the depth, creates challenging mining conditions. The in situ principal stress is horizontal at around $60 \mathrm{MPa}$, with average abutment loads predicted at $80 \mathrm{MPa}$ and maximums exceeding $100 \mathrm{MPa}$. These conditions promote caving, and fragmentation, and caveability of the orebody is not predicted to be an issue.

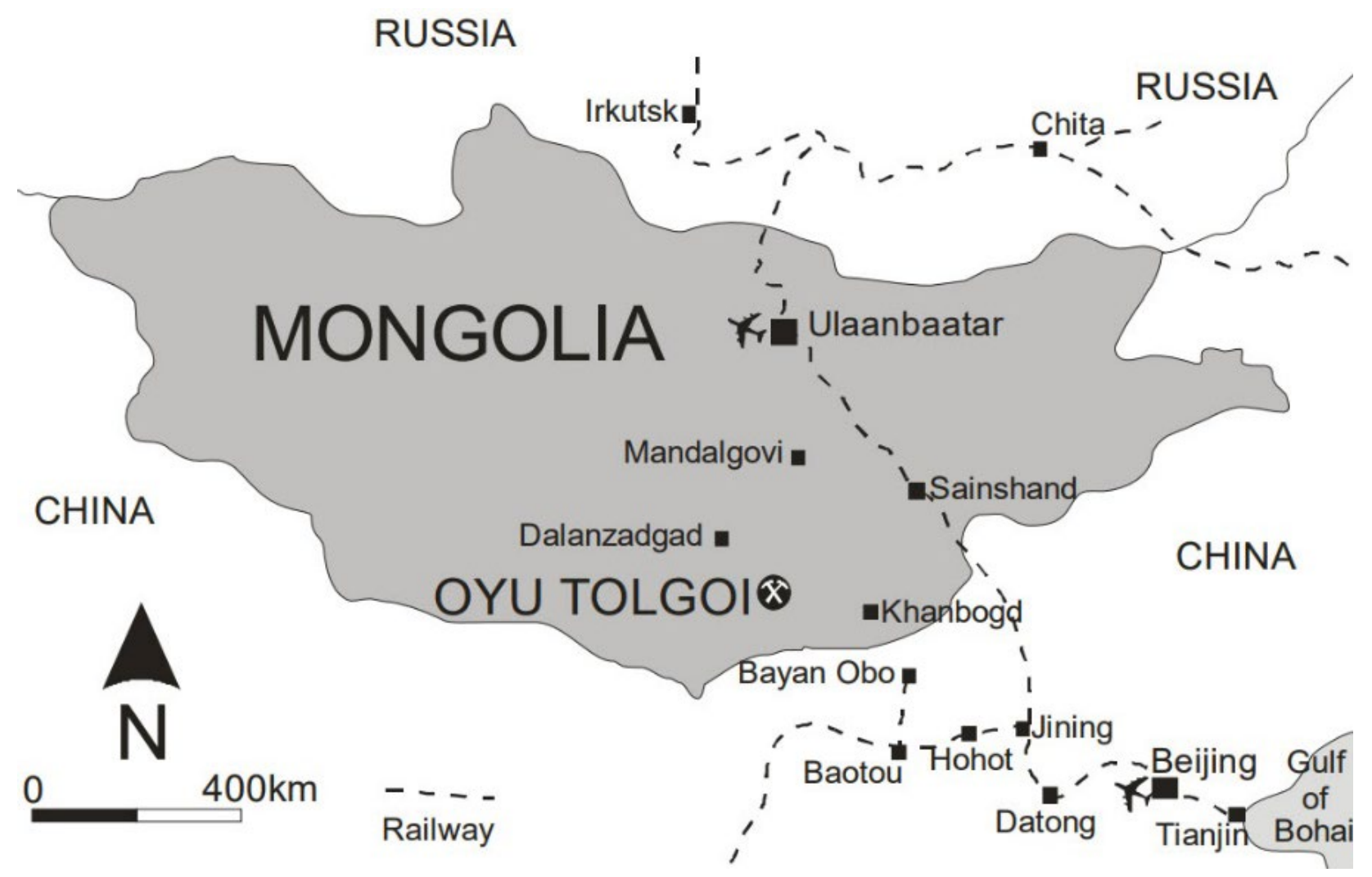

Figure 1 Location of Oyu Tolgoi relative to Ulaanbaatar and China

Hugo North Lift 1 is planned as an advanced undercut cave capable of producing $95 \mathrm{ktpd}$. The Lift 1 mining levels are approximately $1,300 \mathrm{~m}$ below surface. The mine design contains five shafts, $203 \mathrm{~km}$ of lateral development, a $7 \mathrm{~km}$ long dual-conveyor and service decline at an $18 \%$ gradient, $6.8 \mathrm{~km}$ of vertical raiseboring, and $115,000 \mathrm{~m}^{3}$ of mass excavations will be undertaken. The orebody has average dimensions of 2,000 m long $\times 280 \mathrm{~m}$ wide. A total of 2,231 drawpoints are planned to be developed within the mining footprint, accessed from 52 extraction drives. An overview of the mine design is shown in Figure 2.

During the ramp-up to $30 \mathrm{ktpd}$ production, from 2020 through 2022, crushed ore will be conveyed to a storage bin at Shaft 2, where the rock will be loaded into skips and hoisted to the surface. Post-2022, following commissioning of the $95 \mathrm{ktpd}$ conveyor-to-surface system, crushed material will be transferred by incline conveyors from crushers to the surface run-of-mine (ROM) stockpile; the Shaft 2 ore hoist will provide backup capacity during maintenance of the conveyor-to-surface system. Hugo North Lift 1 is scheduled to produce from 2020 to 2039, with a seven year ramp-up to full production (OreWin Pty Ltd 2016).

The key challenge and focus for OT mine scheduling is to use a best practice mine scheduling process to deliver a project into safe production as early as possible, whilst maintaining the long-term business case. 


\section{Mine Footprint}

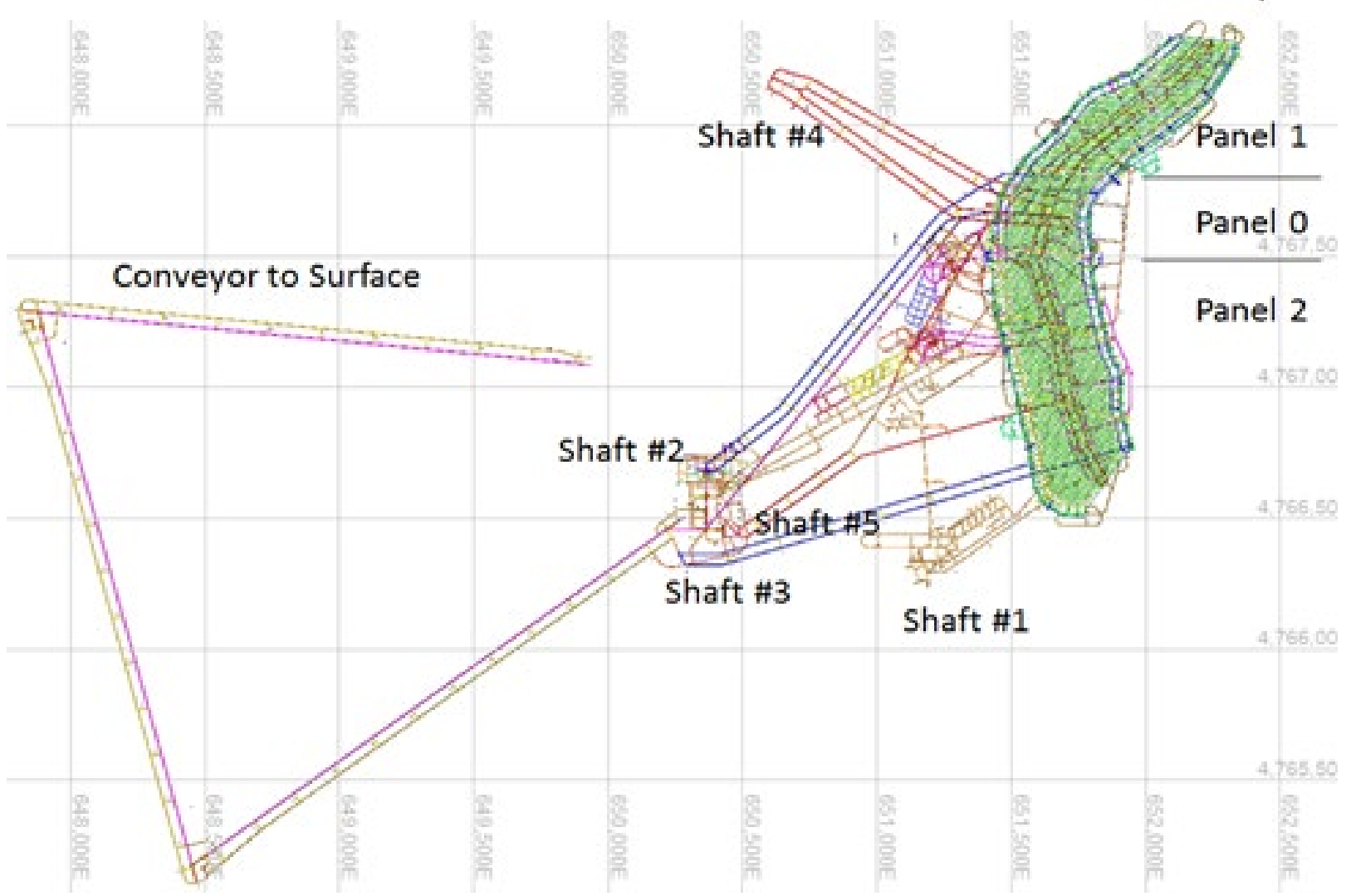

Figure 2 Overview of the underground mine design

\section{$2 \quad$ Management operating system}

OT underground has implemented a management operating system (MOS) to aid the delivery of best for business outcomes. The MOS is centred around creating the perfect shift. It is a structured communication and management process which facilitates delivery of key information across key stakeholders to coordinate and manage the underground development. By doing so, it creates a more effective decision-making process that delivers adequate communication to the right people at the right time. This helps support decision-making as well as bringing more predictable outcomes whilst reducing the risk to the project of poor decision-making. Core to the MOS are the key values of respect, integrity, teamwork and accountability. An overview of the MOS is shown in Figure 3. 

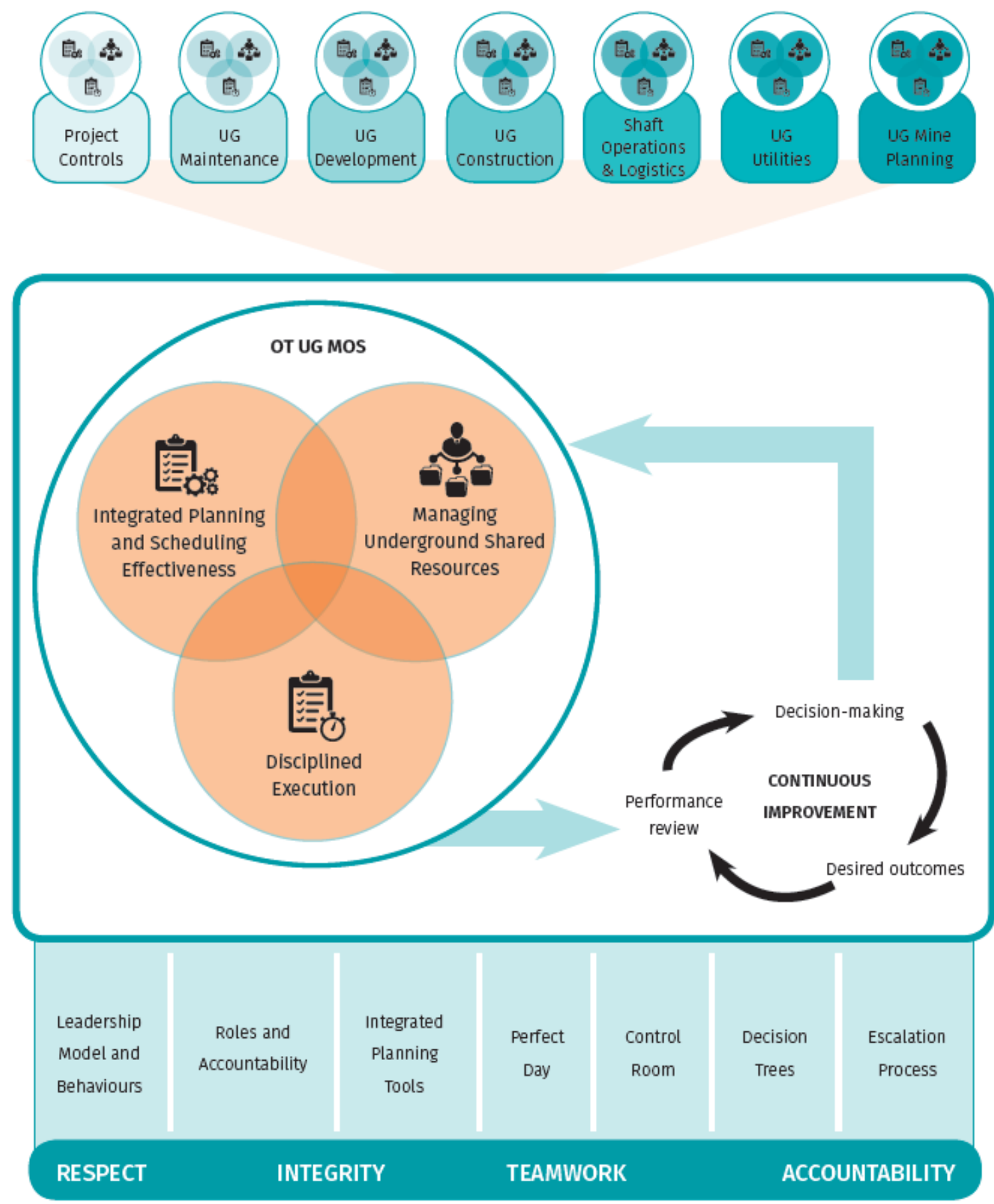

Figure 3 Overview of how the MOS works

A key part of the MOS is the Integrated Planning Process (IPP), which facilitates the delivery of interdependent plans and manages constraints. This is achieved through integrated planning, which operates across various time horizons with an evolving confidence window (lock-in period + forecast impact analysis):

- Annual: 1 year +2 year - Test and optimise major system capacities with a focus on the next 12 months of activity and a forecast of the next two years' capability.

- Quarterly: 3 months +9 months - Understand, map and resolve underground time and space constraints for the quarter and assess the following three quarters.

- Monthly: 1 month + 2 months - Align people, equipment, materials, time and space issues with locked-in resources and identify and escalate any performance deviations or gap closing 
opportunities in the next month with a view of the next two months to achieve the forecast quarterly plan.

- Weekly: 1 week + 1 week - Determine the key scheduled sequencing of logistics and development cycles in conjunction with operational interactions and dependencies for each day of the coming week with a look ahead for the following week.

- Daily: 12 hours + 12 hours - Define an executable perfect shift plan and course correct to achieve the weekly plan.

These plans are developed with input from multiple parties. The key stakeholders in the IPP process are:

- Mining: Operational delivery of mine development.

- Construction: Construction of facilities both on surface and underground.

- Mine planning: Technical accountability for the mine plan delivery and operational design.

- Project controls: Central governance of all aspects of the project focused on cost and schedule delivery.

- Geotechnical: Management of the geotechnical design and QA/QC of implementation.

- Maintenance: Maintenance of all mobile equipment.

- Shaft operations and logistics: Operation management of shafts and logistics delivery.

- Utilities: Operation and maintenance of all Fixed Plant infrastructure - mechanical and electrical.

These parties work together through the IPP process to resolve the key constraints of the project. It has been determined that the key constraints of the OT Underground Project are:

- Availability of shared resources: Multiple resources are shared across work teams in the underground such as ventilation for equipment (i.e. trucking), elevated work platforms and personnel transport which need to be allocated in a manner that delivers best for project outcomes.

- Conflicting project priorities: Conflicts between different working groups' priorities are common on a project of this scale and it is important that these are resolved in a best for project manner to give resources to the group which can make the biggest difference.

- Interdependencies and interactions of tasks: The high complexity of the project results in several interdependencies between activities which must be effectively mapped and managed to deliver best for business outcomes.

- Shaft logistics: Initially the project is constrained to the use of Shaft 1 for all logistics including rock hoisting and man movement which makes the utilisation of this cage a key priority for the project. This requires coordination across all departments to ensure they are able to access their work areas with the correct tools for the job.

- Underground space constraints: Underground space is at a premium as all excavations not directly related to ore extraction use resources which could otherwise be directed to the footprint development, so must have a clear value add benefit to the project.

- Underground access constraints: Activity or congestion in an area of the mine may block or restrict access to secondary activities downstream. The impact to the project of each activity must be evaluated to determine the best for business outcome.

Resolving the aforementioned constraints enables alignment and management of the underground activity. The primary outcome of the IPP process is to develop an integrated plan which highlights areas of potential conflict and resolves these conflicts based on whole of mine priorities to generate an executable delivery plan. 


\section{$3 \quad$ Mine development scheduling}

A best practice mine scheduling process has been implemented for mine development scheduling at OT. The process commences remotely to OT by the Mine Planning and Technical (MPT) team, offsite in Australia. The long-term scheduling is focused on external stakeholder management, which reports a schedule with a $50 \%$ level of confidence (P50). This is referred to as the control schedule. For internal purposes, it was determined that a schedule with a $30 \%$ level of confidence (P30) be developed for execution onsite. This is referred to as the execution schedule. This allows the execution team the ability to plan an upside-case schedule whilst maintaining a central estimate for stakeholders to make business decisions. The main differences between these two schedules, and the feasibility study completed in 2016, are shown in Figure 4 . The control schedule is a central-case (P50) baseline schedule, updated quarterly and scheduled for life-of-mine. The key use is for external communication and updating the long-range project schedule (life-of-mine). In addition, alternative sequence and design options are tested in this schedule to determine the impact on the project. It is an important tool to provide likely mining handover dates to construction and provide project updates for stakeholders.

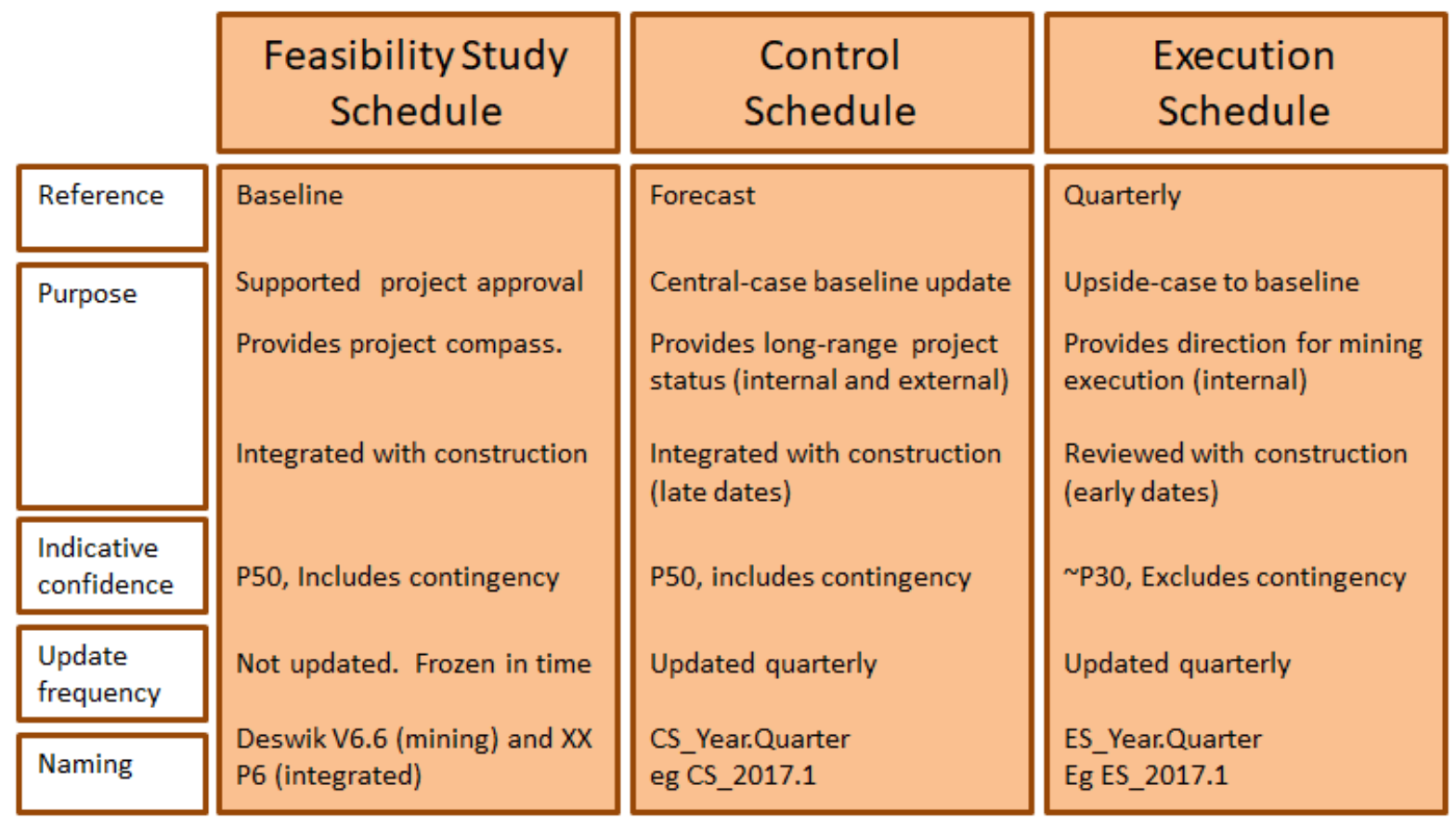

Figure 4 Comparison between feasibility, control and execution schedules

The execution schedule is an upside-case to baseline (P30) and provides direction for mining execution onsite. This schedule is updated quarterly, with key detail for the next 12 months to feed into the annual and quarterly IPP. The primary focus of the plan is spatial location and time of activity with an understanding of ventilation, electrical, water, material handling and pumping constraints. In addition, this provides potential early dates for procurement and contract awarding to flag potential opportunities. The long-term to mid-term planning is undertaken in isolation of the day-to-day pressures of site and allows the team to focus on best for business decisions.

Given the physical separation of the MPT team in Australia from the planning teams onsite in Mongolia, multiple engagement sessions are held between the two teams in the lead-up to the finalisation of the plan. These sessions focus on agreement of schedule constraints and inputs, as well reviewing the schedule outcomes at a 70 and $90 \%$ stage. The scheduling team travels to site during this period, every quarter, to maximise interaction with the site team which ensures that conflicts are resolved early and plans are executable. Following the $90 \%$ schedule review, this is incorporated into the IPP process for formal conflict identification and resolution. In addition, actions may be identified for alternative schedule trade-offs to 
further optimise the schedule, taking into account whole mine priorities. The resolution of these results in the $100 \%$ schedule for sign off and execution.

The plan is transmitted to site in the form of the quarterly execution schedule. Onsite, two teams manage the execution and implementation of the schedule within the three-month timeframe. The Medium Range Planning (MRP) team prepares monthly plans. These are handed down to the Short Range Planning (SRP) team to generate weekly plans. The IPP shift planning team focuses on development of the daily plan with multiple contractors to deliver the best shift plan.

\section{$4 \quad$ Scheduling mechanics}

The generation of a mine development schedule for both execution and control follow the below steps. These are:

1. Input of latest approved mine design.

2. Ground support consumable calculations for the design.

3. Development rate and equipment usage estimation for the design.

4. Derived activity generation of other related activities.

5. Resource levelling of activity levels.

6. Project interfacing review.

The mine development schedule is produced in Deswik using Deswik.CAD, Deswik.IS and Deswik.Sched modules from life-of-mine down to the monthly schedules. Lateral development, vertical development, mass excavation and production designs are updated based on the latest mine design stored in Deswik.MDM. Shorter term planning, including weekly and day-to-day, currently uses alternative software (mainly Microsoft Excel) to achieve the granularity of detail required; alternative scalable solutions are being investigated.

Deswik.MDM is a centralised database that provides OT with one version of the truth for 3D spatial data. It provides storage, communication and visualisation of spatial information with embedded approval and controlled access. Improved safety and productivity outcomes are envisaged by data integration, version control and efficiencies from streamlined processes. Deswik.MDM stores all mine designs as the source of the latest approved mine design for execution and inclusion in the schedule. A combination of tunnels, outlines, and solid creation methods are used to generate task solids to spatially represent activity in the mine. The duration of each development activity in the schedule is determined by its resourcing allocation limited by a maximum development rate. This applies not only to lateral development, but vertical development and mass excavation as well.

The mine development encompasses a range of development profiles, with different ground support complexities based on ground conditions, function and life-of-mine purpose of the drive. Development variables and quantity assumptions are generated for each ground support profile based on the geotechnical design. These form the basis of the estimate for physical profile attributes and dimensions, equipment to be used, ground support factors and drill-and-blast requirements. Ground support consumables are calculated based on a rate per cubic metre and applied to the design inside the schedule for reporting.

Maximum development rates are calculated from a first principles build-up and calibrated with outcomes from Arena simulations, past development performance and benchmarking from other comparable projects. The development cycle time is determined based on the required resource hours to complete the work; this generates an equivalent development cycle rate in metres per day. For headings where blasting can only occur at the end of the shift (due to ventilation) these are rounded to the nearest 12-hour interval. Productivity rate factors are also applied pending the resource allocation method; being a single heading with dedicated resources or one of multiple headings being developed where resources are shared across these. 
Table 1 displays the maximum single heading development rates used at OT for different profiles on footprint. This information forms the basis of schedule rates at a cut-by-cut level and is fed into the schedule via lookup tables, before applying resources and balancing activity in the schedule. Given the detail built into the development rates, the outputs from the schedule also includes equipment performance requirements, ground support consumable and explosives usage forecasting.

\section{Table 1 Development rates}

\begin{tabular}{llll}
\hline & Apex level & Undercut level & Extraction level \\
\hline Drive type & $\begin{array}{l}\text { Drill drive in good } \\
\text { ground }\end{array}$ & $\begin{array}{l}\text { Perimeter drive in } \\
\text { good ground }\end{array}$ & $\begin{array}{l}\text { Extraction drive in } \\
\text { poor ground }\end{array}$ \\
Drive profile & $4.0 \mathrm{~mW} \times 4.2 \mathrm{mH}$ & $5.0 \mathrm{~mW} \times 5.5 \mathrm{mH}$ & $4.5 \mathrm{~mW} \times 4.5 \mathrm{mH}$ \\
Pulled length & 4.5 & 4.9 & 4.5 \\
Volume per cut (m) & 68 & 122 & 83 \\
\hline Task duration (hrs) & & & \\
Loading* & 3.2 & 3.3 & 2.9 \\
Spraying & 1.8 & 3.1 & 2.5 \\
Bolting & 5.4 & 7.2 & 6.6 \\
Cable bolting & 0 & 9.2 & 25.9 \\
Boring & 3.0 & 2.3 & 3.4 \\
Charging & 2.7 & 3.3 & 2.9 \\
\hline Development cycle time (hrs/cut) & 16.1 & 28.4 & 44.3 \\
Effective utilisation (work hrs/shift) & 9.5 & 9.5 & 9.5 \\
Heading turnover duration (hrs) & 24 & 48 & 60 \\
Development rate (m/month) & 108 & 74 & 54 \\
\hline
\end{tabular}

Mine development is scheduled according to development priorities based on when development is required with consideration for resource availability and system constraints, such as hoisting and ventilation. Rules have been built into the schedule around prioritisation of development based on mine area and panel. However, ultimately the prioritisation of activity is semi-manual. At the commencement of each planning cycle (quarterly, monthly, and weekly), variance to plan is reviewed and development priorities adjusted according to actual progress.

Resource allocation for lateral development is split between multiple areas in the mine such as off footprint, apex and undercut levels, the extraction level, the haulage level and mass excavations, whilst vertical development resourcing is more dependent on the excavation methodology. Examples of these include raiseboring, longhole drill-and-blast, and box hole boring. In addition, construction resources are included for tasks such as drawbell construction, edge beams in mass excavations and roadway construction. 
Resource levelling is undertaken on primary system constraints with prioritisation given to project ramp-up priorities considering resource availability. The first constraint applied in the schedule reflects the development material handling capacity constraint from the mine until the permanent material handling system is commissioned. This is implemented as a quantity constraint based on the daily skipping target with consideration for the monthly maintenance schedule. The second constraint is area development limits which have been determined based on available ventilation constraints determined by Ventsim ${ }^{\mathrm{TM}}$ modelling and logistical interactions determined from Arena activity modelling. Constraints have been applied to the footprint levels, both during ramp-up and for steady-state development once production has commenced. Other limiting constraints are determined through schedule engagement sessions and applied to the schedule as detailed work is undertaken to determine their impact, such as constraint on cable bolting metres per month or drawbell ramp-up profile. A key part of each schedule review is to challenge constraint assumptions and identify opportunities for improvement.

In addition to lateral development, other derived activities are captured in the schedule to assist with identifying conflicting activities. Visualisation of these additional tasks helps identify activity in an area. For example, intensive ground support is designed on footprint and in mass excavation chambers which can be completed after the initial development cycle. A derived activity for this work allows visualisation which assists the scheduling of these additional passes of ground support installs such as, but not limited to, spraying of second pass shotcrete, cable bolt installation, and curing. Additionally, if the install sequence allows, these are grouped together to campaign the installation which increases equipment productivities in a development heading. The mine schedule includes derived activities for the following work:

- Ground support: second, third and fourth pass ground support plus intersection and mass excavation cables.

- Raiseboring: concrete pad construction, set-up, piloting and rig-down.

- Production drilling for undercut rings (prior to detailed design).

- Construction: drawbells, haulage chutes and edge beams.

- Interfaces: start, finish and handover dates for an area of interest.

Rates for these derived activities are calculated from first principles; the same as the development rates.

The detailed task information of each schedule iteration is uploaded to an SQL database. Tableau, a web-based interactive data visualisation solution, is then used to undertake secondary level capacity checks and generate schedule dashboards for communication of key schedule outcomes. For example, validating ventilation requirements from equipment hours and trucking movements is undertaken in a Tableau sheet, while standard output charts such as development metres per month and hoisted tonnes per month are generated. An example of equipment capacity checks is shown in Figures 5 and 6 . Figure 5 shows the delta between available equipment (based on maintenance and procurement schedules) to required equipment which allows conflicts to be rapidly identified. Figure 6 shows graphically the equipment required versus the available equipment, which better identifies which equipment should be closely monitored. Overall, this reporting framework allows for automated repeatability of schedule outputs, facilitates quick communication of information to stakeholders and enables self-service for decision-makers. 


\begin{tabular}{|c|c|c|c|c|c|c|c|c|c|c|c|c|}
\hline Equipment Type & Jul & Aug & Sep & Oct & Nov & Dec & Jan & Feb & Mar & Apl & May & Jun \\
\hline Charging & 1 & 1 & 1 & 1 & 1 & 1 & 5 & 5 & 5 & 4 & 4 & 4 \\
\hline 2.4_Bolters & 2 & 2 & 2 & 2 & 2 & 2 & 2 & 2 & 2 & 2 & 2 & 2 \\
\hline 2.4FTP_Bolters & 2 & 3 & 4 & 4 & 3 & 4 & 4 & 4 & 4 & 4 & 4 & 4 \\
\hline 3.0_Bolters & 2 & 2 & 2 & 1 & 1 & 2 & 1 & 1 & 2 & 1 & 1 & 0 \\
\hline 410LHD & 1 & 1 & 1 & 1 & 1 & 3 & 3 & 3 & 3 & 3 & 3 & 3 \\
\hline 514LHD & 1 & 1 & 1 & 1 & 1 & 1 & 1 & 3 & 3 & 3 & 3 & 3 \\
\hline 517LHD & 4 & 4 & 3 & 4 & 4 & 4 & 4 & 4 & 4 & 3 & 3 & 3 \\
\hline AgitatorTrucks & 4 & 3 & 3 & 6 & 6 & 6 & 6 & 6 & 6 & 5 & 5 & 4 \\
\hline FTP Cablebolting & 0 & 0 & 2 & 2 & 1 & 1 & 1 & 0 & -1 & 2 & 1 & 1 \\
\hline FTP_FaceDrills & 0 & 0 & 3 & 3 & 3 & 3 & 3 & 3 & 3 & 3 & 3 & 3 \\
\hline ShotcreteMachine & 3 & 4 & 3 & 4 & 4 & 4 & 4 & 4 & 4 & 4 & 4 & 3 \\
\hline STN Cablebolting & 0 & 0 & 0 & 0 & 0 & 0 & 0 & 1 & 1 & 1 & 3 & 1 \\
\hline STN_FaceDrills & 4 & 4 & 4 & 4 & 4 & 4 & 4 & 4 & 4 & 4 & 4 & 4 \\
\hline Trucking & 2 & 4 & 4 & 4 & 4 & 4 & 4 & 4 & 4 & 3 & 3 & 2 \\
\hline
\end{tabular}

Figure 5 Equipment area of concern table showing available equipment less required equipment. Positive values indicate available capacity and negative values indicate areas of concern 


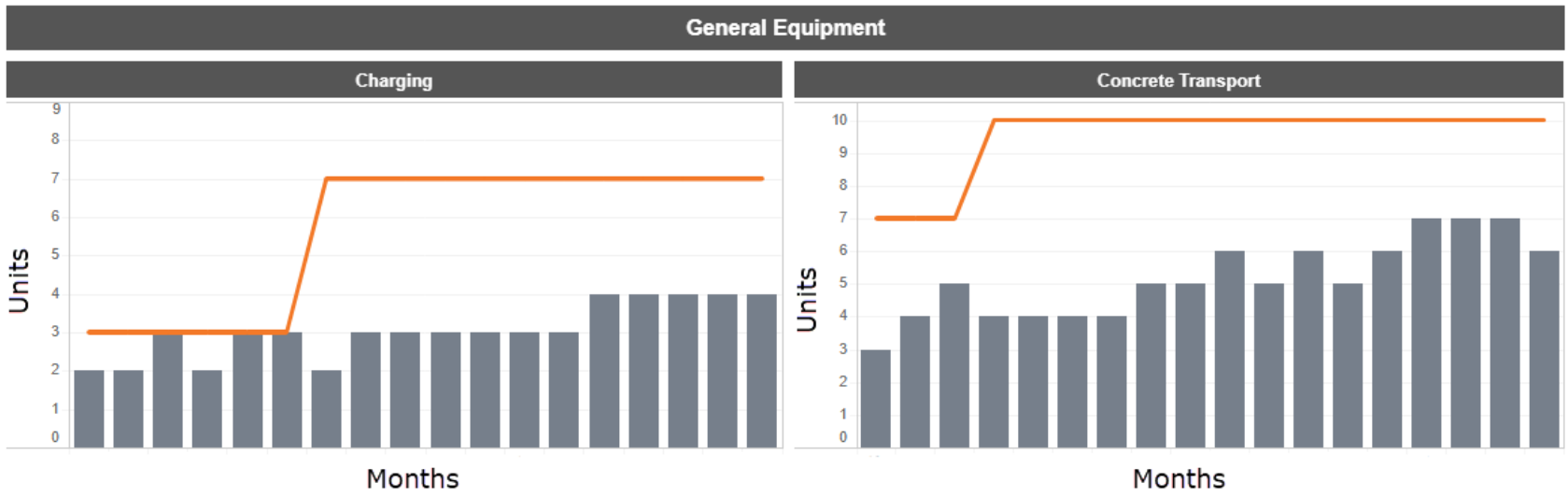

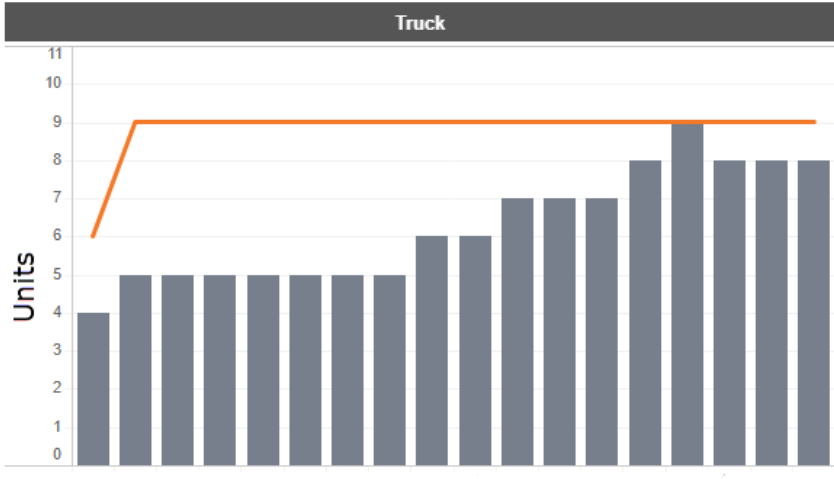

Months

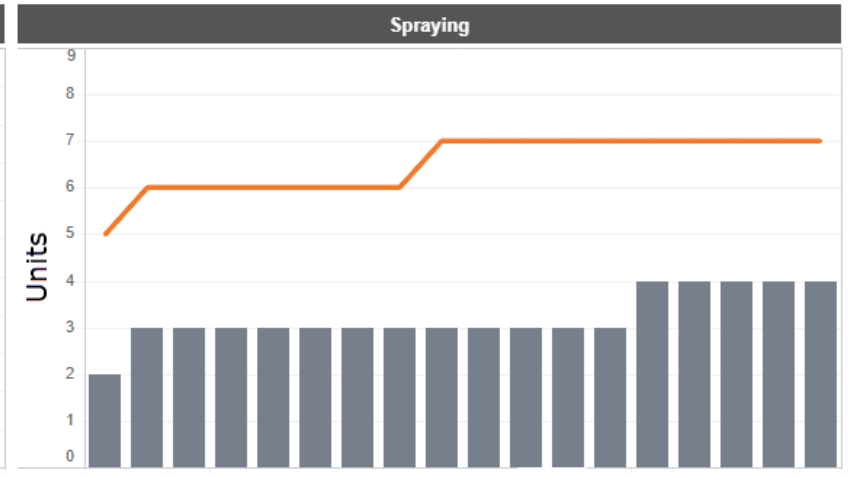

Months

Figure 6 Available equipment (solid line) versus required equipment (bars), excluding productivity learning curves

To quickly determine the impact of a mining schedule on the overall project, an interfacing framework for the project critical path and construction interfaces with relevant logic has been built inside the mining schedule. Physical solids, referred to as interfaces, have been built around underground development milestones in the Deswik schedule. This allows a visual reference for project interfaces as well as the ability to generate task dependencies. These solids are spatially linked to the encompassed development tasks and assist with showing start and finish dates of mining for an area whilst allowing for potential sequence changes through an area. In addition, handover to construction durations are added, as well as summary construction activities based on the level of effort tasks in the construction schedule. Linking between schedules is achieved by a unique interface code. Addition logic is developed in the schedule to logically link key interfaces pending their project requirements; these may be finish-start, start-start or finish-finish dependency types. An example of this is where an electrical cable is required to energise a substation critical for the production crusher. The crusher cannot be commissioned without the substation to power it, and the substation requires the electrical cable to be energised. However, the electrical cable run cannot occur until the development is complete for that area. An interface is created for each of these development scenarios, then linked as finish-start dependencies to understand the commissioning date for the production crusher. An example of this can be seen in the logic diagram in Figure 7, with a spatial representation in Figure 8. 


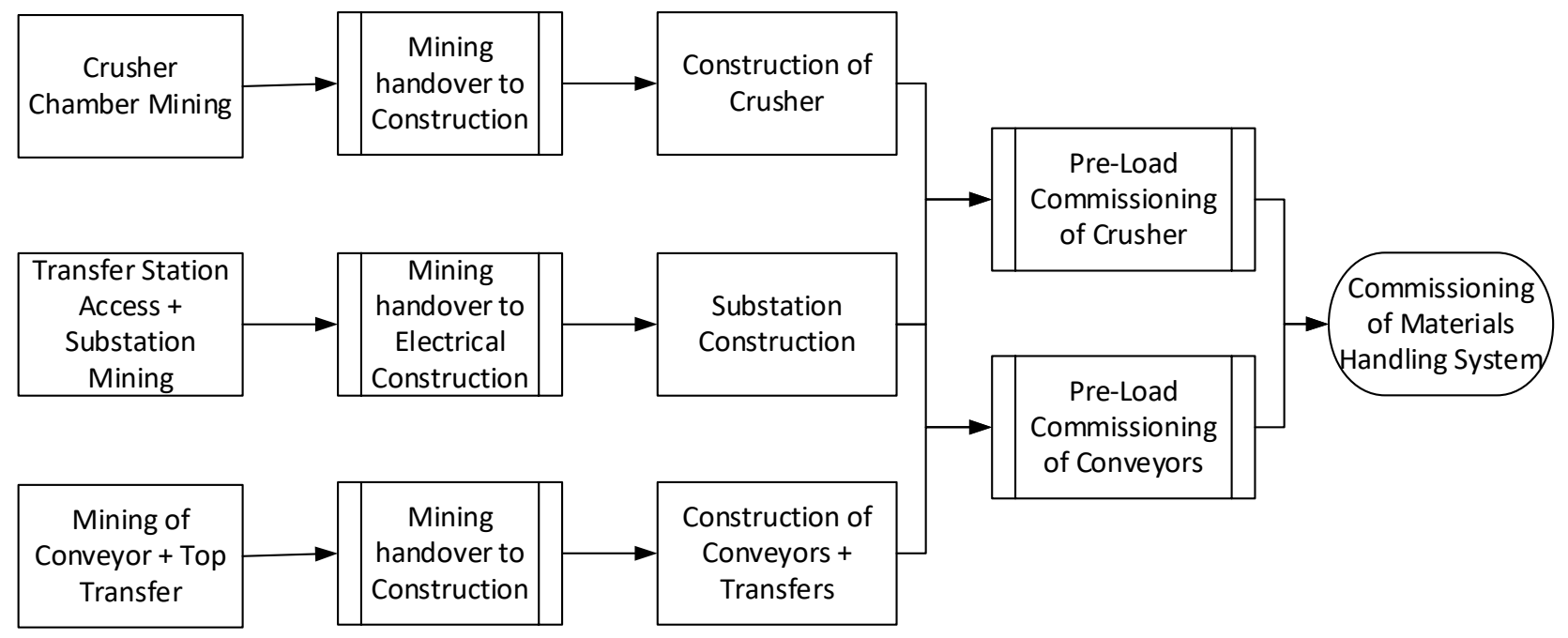

Figure 7 Interface logic for the materials handling system at crusher 1

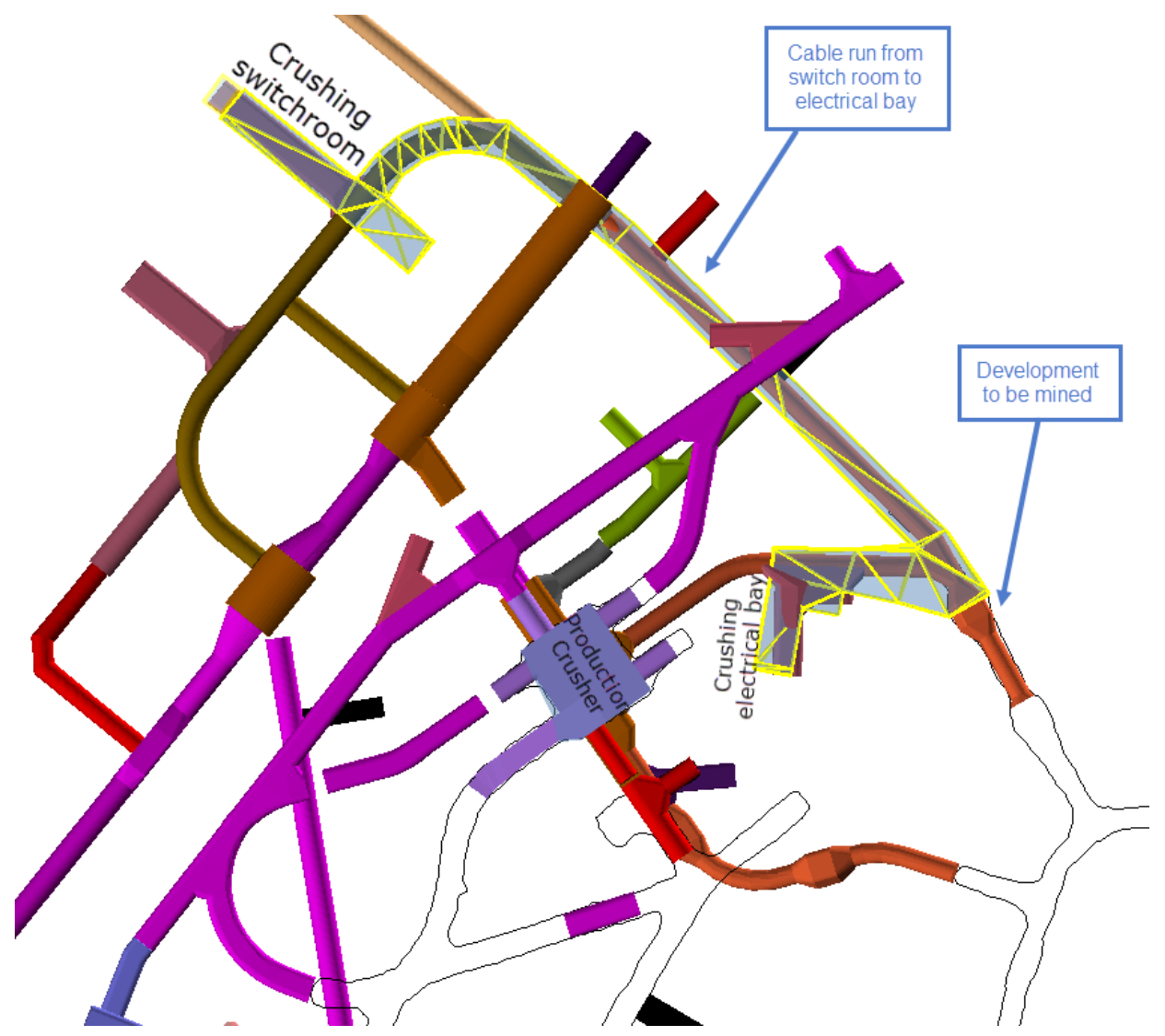

Figure 8 Example of interface solid for cable route highlighted around development activity

Another example of how the milestones are treated with parallel tasks is shown in Figure 9 for the Slickline Receiving Facility (SLRF). A drillhole is required from surface to underground, while simultaneously, underground development is mined to enable the breakthrough and reaming phase of the drillhole. The remainder of the development is completed once the drillhole has been lined, then handed over to construction. The logic is all linked together to a final facility delivery date which allows variances to be easily highlighted and the cause of the schedule variance to be quickly identified. 


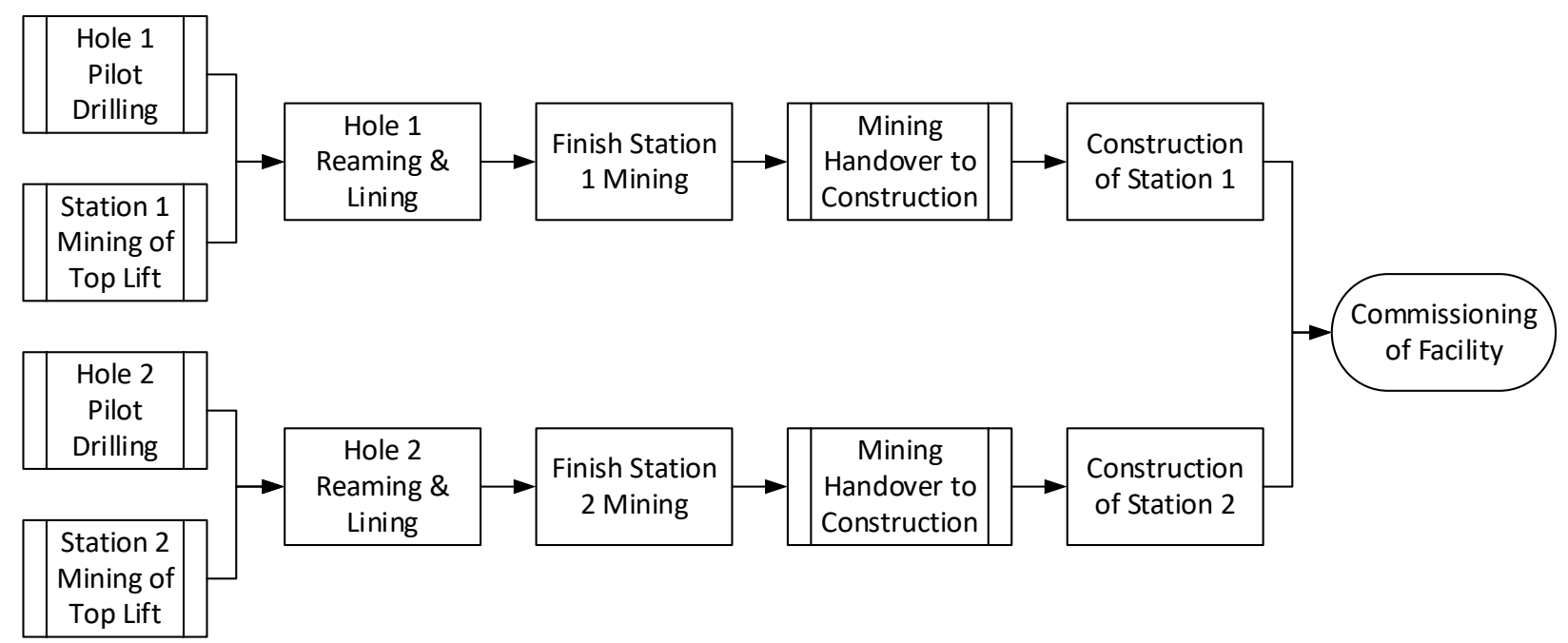

Figure 19 Interface logic for SLRF

Change variance between schedules is determined by baselining and analysis of changes in interface dates. A schedule can be baselined between iterations to provide a quick reference on areas of slippage in a Gannt format. Additionally, the interfacing task information is loaded to an SQL database for variance analysis in Tableau to compare handover dates between schedule iterations. This highlights project sensitivities and critical paths for the schedule, which is critical due to the high capital cost and long construction period for caving. Further, by loading to an online platform, information can be quickly accessed by all parties when required.

The overall intent of mine development scheduling is to maintain a sufficient level of detail to deliver a safe, productive and reliable mine development. Further work continues on the journey to achieving the perfect shift, which includes, but is not limited to, schedule reconciliation with data analytics, mine schedule optimisation, automated conflict detection and resolution, detailed production scheduling, and increased integration across project functions and improved access and communication of the schedule to all impacted parties.

\section{Compliance to plan}

Schedules are reviewed periodically throughout the planning cycle and compliance to schedule is documented at different time horizons against the relevant schedule. It is an important part of the planning cycle, and understanding the deviation and actioning to bring tasks back on schedule is critical to the success of the project. A high-level compliance figure is generated for each month based on metres completed per heading versus metres planned per heading. This is then weighted by the proportion of metres in a heading versus the total in the plan. This is predominately used as a reporting mechanism.

Daily actuals are tracked against the plan by each responsible department; for example, maintenance track breakdown time per equipment, geotechnical track overbreak compliance on each cut, and the overall project meeting tracks total tonnes hoisted (as the primary constraint).

The planning team prefers to talk through variances to plan based on a spatial representation of activity where it is tracked and monitored at weekly, monthly and quarterly levels. This involves the generation of spatial compliance plots, using a standard colour key to communicate this information effectively. Figure 10 shows tasks coloured relevant to their category at the end of the designated period, being either planned and not achieved, not planned and achieved, planned and achieved, or outside the quarterly forecast. Survey data is also uploaded to Tableau to compare against the plan, most commonly by heading, mine area or work breakdown structure (WBS) code. 


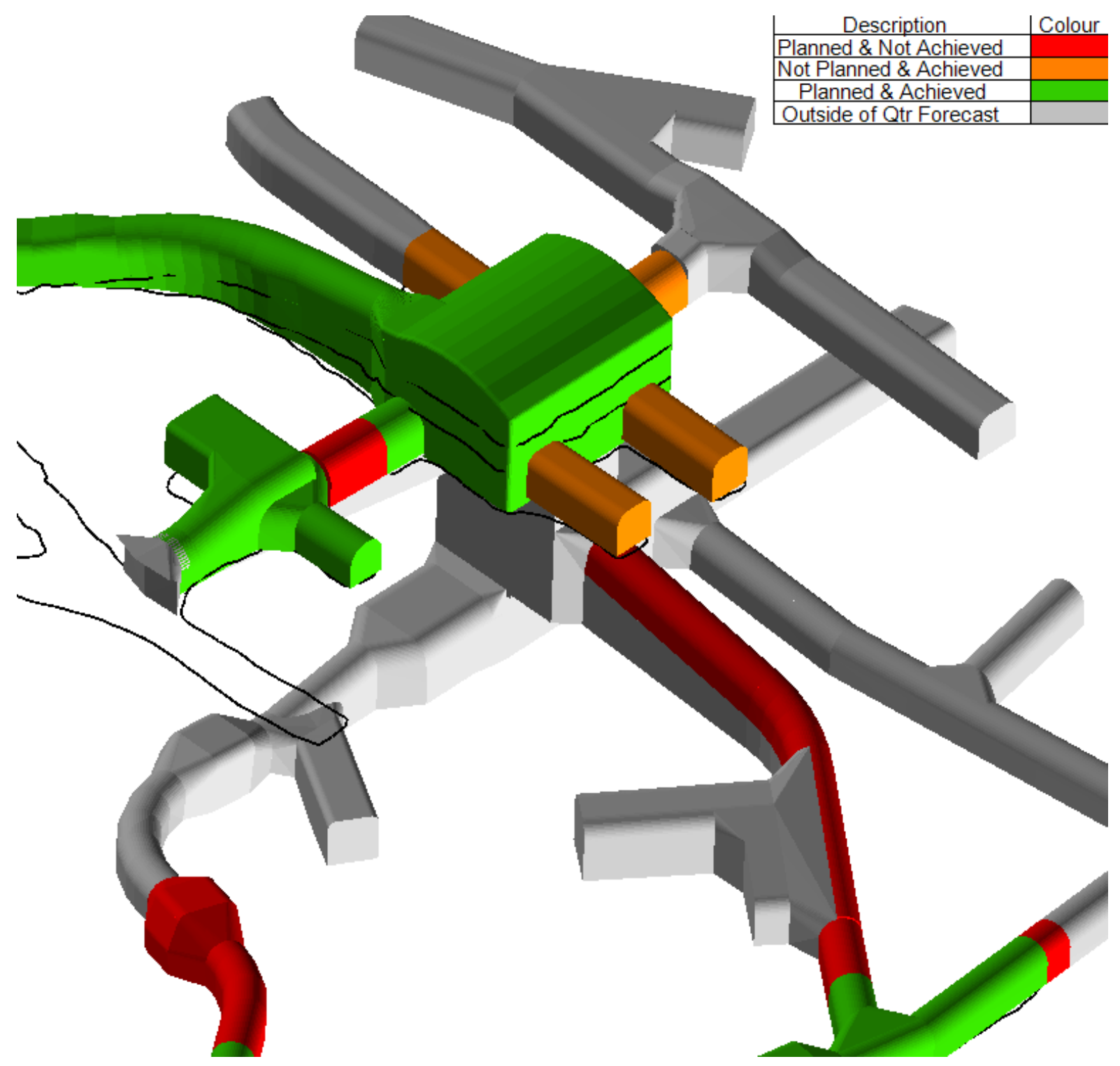

Figure 102 Compliance plot - isometric view of production crusher 1

\section{$6 \quad$ Future work}

Continuous improvement is embedded into the culture of the mine planning team. Some of the future projects currently being investigated are:

- Use of an optimisation engine to semi-automate the generation of mining schedules, in particular, priority generation.

- Integration of the schedule into Deswik.MDM to enable the schedule to be parsed out into various mining areas to improve the ability for multiple users to adjust the schedule.

- Development of an integrated planning solution for the short-term space to automate multiple manual processes, automate conflict and interaction detection, and potentially dynamic scheduling of activities.

- Streamlining of schedule adjustment process around incorporation of new mine designs, adjustment of schedule logic and progressing schedule progress.

- Automated comparisons of actual performance to planned performance with the ability to drill down to first principles detail, i.e. rig-up/rig-down times and penetration rates. 


\section{Conclusion}

The business aims to implement best practice mine scheduling coupled with a MOS to deliver the perfect shift every shift for the site team to execute. A collaborative effort across multiple stakeholders seeks to align the schedule prior to implementation. Two long-term mine schedules are generated quarterly to provide central and upside estimates of performance for project stakeholders and site execution teams, respectively. The site team manages the execution and implementation of the mine schedule in the three-month timeframe. The schedules contain first principle build-ups of activity cycle times calibrated from actual data captured, which allow activities to be resource levelled to balance system constraints and prioritise activity for best of business outcomes. In addition, information on early and late dates for activities is communicated via an online platform for decision-making. Overall, it is intended that plans are deconflicted as early as possible to promote a safe, productive and reliable mine development.

\section{Acknowledgement}

The authors acknowledge the Oyu Tolgoi Mine Planning and Technical team, as well as the entire project team in Mongolia, for the opportunity to write this paper and their aid in acquiring the information. In particular, the ongoing support of Troy Newman and Andy McGrath continues to enable the team to develop the system and processes to deliver best for business outcomes. Additionally, the authors acknowledge the feasibility study team and the foundation they established for the project.

\section{References}

OreWin Pty Ltd 2016, Oyu Tolgoi 2016 Oyu Tolgoi Technical Report, October 2016, Job No. 15016, OreWin Pty Ltd, Adelaide, viewed 28 April 2018, http://www.turquoisehill.com/i/pdf/2016-10-tr-trq-r77gvc.pdf 
